\title{
An Analysis of Activity, Intensity and Structural Effect on Change in Energy Consumption in Bangladesh using Complete Decomposition Model (CDM)
}

\author{
S. Khosruzzaman , M. A. Asgar ${ }^{\text {b }}$, M. A. Asgar , K. M. R. Rahman ${ }^{\text {d }}$ and S. Akbar \\ ${ }^{a}$ Institute of Natural Sciences, National University, Gazipur, ${ }^{b}$ Uttara University, Dhaka, ${ }^{c}$ East-West University, \\ Dhaka, ${ }^{d}$ Bangladesh Atomic Energy Commission, Dhaka, Bangladesh
}

\begin{abstract}
For the purpose of identifying the vulnerable aspects of our energy problem and to seek an appropriate solution, the total energy supply, energy demand and energy consumption need to be analyzed in respect of their components. We have used the decomposition model for analyzing the correlation between energy consumption and economic development up to 2007 taking 1990 as the base year. The relative impacts of activity, intensity and structure effect are analyzed for different economic sectors in Bangladesh. Moreover, the country's economy is disaggregated in to two groups' namely low energy intensive group and high-energy intensive group. The trends of energy uses in the above groups are also evaluated to provide a basis for assessment of sustainability.
\end{abstract}

Key words : Complete decomposition model, Energy consumption, Energy intensity, Activity effect, Structural effect, Intensity effect.

\section{Introduction}

The decomposition method is used to analyze the impact of different economic sectors in respect of activity, intensity and structure of energy uses. In order to optimize the use of energy, it is important that we separate out the influence of different factors of the total economy as dependent on energy. The different components are identified as activity effect, structural effect and intensity effect which in fact represent the economic growth, changing the pattern of economy and the efficiency of the use of energy respectively. In order to plan the use of energy in respect of its impact on the aggregated economy, the three effects as defined above are to be considered separately for different economic activities. It is then easer for the planner to decide the optimum path of development in respect of energy input. For Bangladesh one has to find the optimum path of energy use by considering its present state of development and its resources in respect of manpower, materials and available technology. We need to find a solution, which is optimum for all its characteristics. Thus, the decomposition approach is more appropriate to explain the effect of energy planning on the development of Bangladesh, as in other countries, in an appropriate way.

Activity effect describes the effect of changes in total production without the impacts from structural and technological factors. Activity effect refers to overall growth of the economy as measured by GDP. It describes the degree of sectoral contribution in the total economy. Positive trends of the sectoral activity reflect the positive contribution. The relative growth of activity effect of different sectors describes the relative contribution of those sectors in the total GDP.

Structural effect describes the sectoral contribution to the total economy and through indicating the structural change of a sector in terms of energy consumption. More energy intensive structural change means creation of large-scale new industrial activity with large employment opportunity. The positive trends of the structural effect reflects the positive growth of GDP, however, more energy will be required for increasing the GDP.

The energy intensity effect measures the improvement in energy efficiency, changes in technology, fuel mix changes, and other factors that are not related to activity or structure. Intensity effect describes the structural change towards energy intensive sector, which means lower intensity, but for creating a new large scale industrial opportunity the intensity would be much lower than the base year. A positive intensity effect signifies a higher energy use per unit of GDP, implying worsening energy efficiency. A negative intensity effect indicates an improvement in energy use per unit of GDP. The negative intensity should be realized in order to sustain the sustainable development of energy sectors. 
The economy of any nation can be disaggregating into two groups: one consisting of low-energy intensive sectors and other consist of high-energy intensive sectors. When decomposition model is applied at the level one, it is called single level decomposition or decomposition at group level. If decomposition is carried out at more than one level it is called multilevel decomposition. Each group could be further disaggregated into several sectors, and then decomposed at sector level, which is attributed to the decomposition level two. For the present analysis multi level decomposition model is used to estimate the change in energy consumption and change in energy intensity in Bangladesh.

Basically, the decomposition models lead to an approximate decomposition. This type of decomposition methods have been proposed by Reitler et al. (1987), Boyd et al. (1988), Doblin and Claire (1988), Howarth (1991), Howarth and Schipper (1992), Park $(1992,1993)$ and so on. These approximate decomposition methods have some inherent limitations. J.W Sun (1996) developed a Complete Decomposition Model (CDM) that can provide us with more reliable and accurate data of the development of the energy basis of an economy.

In this paper we have made an effort for the first time to use the decomposition technique at the national level to analyze the development of energy base of the economy in practice with reference to Bangladesh. In this study we decomposed the change in energy consumption and energy intensity in Bangladesh during 1990 to 2007. The change in energy consumption is decomposed into the scale of economic activity (the activity effect), the economic structure (the structural effect) and the sectoral technological level (the intensity effect). The change of energy intensity is decomposed into sectoral energy intensity effect and sectoral structural effect.

The complete decomposition model is used in our study to describe (1) the change of energy consumption in Bangladesh; (2) the change of energy intensity in Bangladesh and (3) the contribution of activity, structural and intensity effect quantitatively for providing a basis of the assessments of sustainability.

\section{Materials and Methods}

We have used the available up-to-date data from different national and international sources like Bangladesh bureau of statistics, PDB, Petrobangla, ADB, and WB etc. The annual data of Gross Domestic Product is converted into US\$ of
2000. The GDP and commercial energy consumption of 1990 is considered as base value.

The general decomposition model leads to an approximate decomposition because it has a residual term. In some studies the residual was omitted that caused a large estimation error. The residual was regarded as an interaction term that still leaves a new puzzle for analysis. The complete decomposition model (CDM) is expected to overcome this problem.

In the decomposition approach, changes in energy intensity between the base year and year $t$ are influenced by intensity and structure effects which are given below:

$$
\begin{aligned}
\Delta \mathrm{I}_{\mathrm{ot}} & =\mathrm{I}_{\mathrm{t}}-\mathrm{I}_{\mathrm{o}} \\
& =\sum\left(\Delta \mathrm{S}_{\mathrm{it}} \mathrm{I}_{\mathrm{io}}\right)+\sum\left(\mathrm{S}_{\mathrm{io}} \Delta \mathrm{I}_{\mathrm{it}}\right)+\sum\left(\Delta \mathrm{S}_{\mathrm{it}} \Delta \mathrm{I}_{\mathrm{it}}\right) \\
& =\mathrm{S}_{\text {effect }}+\mathrm{I}_{\text {effect }}
\end{aligned}
$$

This is an exact decomposition, where

Structural effect $\left(\mathrm{S}_{\text {effect }}\right)=\Sigma\left(\Delta \mathrm{S}_{\mathrm{it}} \Delta \mathrm{I}_{\mathrm{io}}\right)+(1 / 2) \Sigma\left(\Delta \mathrm{S}_{\mathrm{it}} \Delta \mathrm{I}_{\mathrm{io}}\right)$ and

Intensity effect $\left(\mathrm{I}_{\text {effect }}\right)=\Sigma\left(\Delta \mathrm{S}_{\text {io }} \Delta \mathrm{I}_{\mathrm{it}}\right)+(1 / 2) \Sigma\left(\Delta \mathrm{S}_{\mathrm{it}} \Delta \mathrm{I}_{\mathrm{it}}\right)$

Here,

$\mathrm{I}_{\mathrm{io}}+\mathrm{I}_{\mathrm{i}}, \mathrm{I}_{\mathrm{io}}=$ energy intensity of sector $\mathrm{i}$ in year $\mathrm{t}$ and 0 , respectively

$\mathrm{S}_{\mathrm{io}}+\Delta \mathrm{S}_{\mathrm{it}}, \mathrm{S}_{\mathrm{io}}=$ output share of sector $\mathrm{i}$ in year $\mathrm{t}$ and 0

$\Delta \mathrm{S}_{\mathrm{it}}=\Delta \mathrm{S}_{\mathrm{it}}-\mathrm{S}_{\mathrm{io}}$ and

$\Delta \mathrm{I}_{\text {it }}=\mathrm{I}_{\text {it }}-\mathrm{I}_{\text {io }}$

The first term of equation-1 indicates the contribution of change in energy intensity in sector $i$. The second term represent the contribution of changes in sectoral share of sector $\mathrm{i}$, while third term indicates the interaction between both factor changes in sector $\mathrm{i}$.

In the decomposition approach, changes in energy consumption between the base year and year $t$ are influenced by activity (GDP), intensity and structure effects as given below:

$$
\begin{aligned}
\Delta \mathrm{E}_{\mathrm{ot}}= & \mathrm{E}_{\mathrm{t}}-\mathrm{E}_{\mathrm{o}} \\
= & \Sigma\left(\Delta \mathrm{A}_{\mathrm{t}} \mathrm{S}_{\mathrm{io}} \mathrm{I}_{\mathrm{io}}\right)+\Sigma\left(\mathrm{A}_{\mathrm{o}} \Delta \mathrm{S}_{\mathrm{it}} \mathrm{I}_{\mathrm{io}}\right)+\Sigma\left(\mathrm{A}_{\mathrm{o}} \mathrm{S}_{\mathrm{io}} \Delta \mathrm{I}_{\mathrm{it}}\right)+ \\
& \Sigma\left(\Delta \mathrm{A}_{\mathrm{t}} \Delta \mathrm{S}_{\mathrm{it}} \mathrm{I}_{\mathrm{io}}\right) \\
& +\Sigma\left(\mathrm{A}_{\mathrm{o}} \Delta \mathrm{S}_{\mathrm{it}} \Delta \mathrm{I}_{\mathrm{it}}\right)+\Sigma\left(\Delta \mathrm{A}_{\mathrm{t}} \mathrm{S}_{\mathrm{io}} \Delta \mathrm{I}_{\mathrm{it}}\right)+\Sigma\left(\Delta \mathrm{A}_{\mathrm{t}} \Delta \mathrm{S}_{\mathrm{it}} \Delta \mathrm{I}_{\mathrm{it}}\right) \\
= & \mathrm{GDP}_{\text {effect }}+\mathrm{S}_{\text {effect }}+\mathrm{I}_{\text {effect }}
\end{aligned}
$$

This is an exact decomposition, where

The activity effect (GDP effect $)$

$$
\begin{aligned}
= & \Sigma\left(\Delta \mathrm{A}_{\mathrm{t}} \mathrm{S}_{\mathrm{io}} \mathrm{I}_{\mathrm{io}}\right)+(1 / 2) \Sigma \Delta \mathrm{A}_{\mathrm{t}}\left(\mathrm{S}_{\mathrm{io}} \Delta \mathrm{I}_{\mathrm{it}}+\Delta \mathrm{S}_{\mathrm{it}} \mathrm{I}_{\mathrm{io}}\right) \\
& +(1 / 3) \Sigma\left(\Delta \mathrm{A}_{\mathrm{t}} \Delta \mathrm{S}_{\mathrm{it}} \Delta \mathrm{I}_{\mathrm{it}}\right)
\end{aligned}
$$


The structural effect $\left(\mathrm{S}_{\text {effect }}\right)$

$$
\begin{aligned}
= & \Sigma\left(\mathrm{A}_{\mathrm{o}} \mathrm{S}_{\mathrm{it}} \mathrm{I}_{\mathrm{io}}\right)+(1 / 2) \Sigma \Delta \mathrm{S}_{\mathrm{it}}\left(\mathrm{A}_{\mathrm{o}} \Delta \mathrm{I}_{\mathrm{it}}+\Delta \mathrm{A}_{\mathrm{t}} \mathrm{I}_{\mathrm{io}}\right) \\
& +(1 / 3) \Sigma\left(\Delta \mathrm{A}_{\mathrm{t}} \Delta \mathrm{S}_{\mathrm{it}} \Delta \mathrm{I}_{\mathrm{it}}\right)
\end{aligned}
$$

and The intensity effect $\left(\mathrm{I}_{\text {effect }}\right)$

$$
\begin{aligned}
= & \Sigma\left(\mathrm{A}_{\mathrm{o}} \mathrm{S}_{\mathrm{io}} \mathrm{I}_{\mathrm{it}}\right)+(1 / 2) \Sigma \Delta \mathrm{I}_{\mathrm{it}}\left(\mathrm{A}_{\mathrm{o}} \Delta \mathrm{S}_{\mathrm{it}}+\Delta \mathrm{A}_{\mathrm{t}} \mathrm{S}_{\mathrm{io}}\right) \\
& +(1 / 3) \Sigma\left(\Delta \mathrm{A}_{\mathrm{t}} \Delta \mathrm{S}_{\mathrm{it}} \Delta \mathrm{I}_{\mathrm{it}}\right)
\end{aligned}
$$

Here, $E_{t}, E 0$ is total energy used in year $t$ and 0 (base year) and $\mathrm{I}_{\mathrm{io}}+\Delta \mathrm{I}_{\mathrm{it}}, \mathrm{I}_{\mathrm{io}}$ is energy intensity of sector $\mathrm{i}$ in year $\mathrm{t}$ and 0 , respectively. $\mathrm{S}_{\text {io }}+\Delta \mathrm{S}_{\mathrm{it}}, \mathrm{S}_{\mathrm{io}}$ stands for output share of sector $\mathrm{i}$ in year $\mathrm{t}$ and 0 and $\mathrm{A}_{\mathrm{o}}+\Delta \mathrm{A}_{\mathrm{t}}, \mathrm{A}_{\mathrm{o}}$ stands for the level of aggregated activity in year $t$ and 0 . We have defined the change of activity, $\Delta \mathrm{A}_{t}$; change of structure, $\mathrm{S}_{\mathrm{it}}$ and change of intensity, $I_{i t}$ parameters in the following way:

$$
\begin{aligned}
& \Delta \mathrm{A}_{\mathrm{t}}=\mathrm{A}_{\mathrm{t}}-\mathrm{A}_{0} \\
& \Delta \mathrm{S}_{\mathrm{io}}=\mathrm{S}_{\mathrm{it}}-\mathrm{S}_{\mathrm{io}} \text { and } \Delta \mathrm{I}_{\mathrm{it}}=\mathrm{I}_{\mathrm{it}}-\mathrm{I}_{\mathrm{io}} .
\end{aligned}
$$

The first terms of the above three equations represent the contributions of the change of GDP, sectoral share and intensity respectively to the total change in energy consumption. The second term represents the contribution of the change of one factor with sum of the partial changes of other two factors with respect to sector $\mathrm{i}$. The third term is the residual in the general decomposition model. It could be attributed either to GDP, sectoral share and intensity by equal impact. This contribution is dependent on all of the three changes, and if only one of them goes to zero the other effects disappears.

\section{Results and Discussion}

The commercial energy consumption in Bangladesh increased by 5.98 fold, which is greater than the GDP growth (2.4 fold) during the period 1990-2007, shown in table I. At the same time the aggregate energy intensity of the national economy increased by 2.6 times of the base year. In our calculation the energy consumption in group-1 (low energy intensive sector which comprise agriculture) appeared to increase by 10 fold in the period 1990 to 2007, while in group-2 (high energy intensive sector which comprise industry, service and transport) the corresponding increase is 5.7 fold. The GDP of group-1, 1.7 fold increased in the period 1990 to 2007, while in group-2, the corresponding factor is 2.6 fold. The energy intensity of low energy intensive group increased by 6.6 fold during the period 1990 to 2007, on the other hand the energy intensity in high-energy intensive group increased by 2.3 fold during the same period as shown in Table I.

For the total intensity change, structural effect is found to be positive in all sub period and intensity effect is also negative in the period 1991 to 1995 , come positive in the period 1995 to 2007, shown in Table II. The structural effect and intensity effect are both positive during the whole period (19912007). The energy intensity increased by $0.37 \mathrm{KGOE} / \mathrm{US} \$$ $(18.6 \%)$ due to structural effect and there was 1.62 KGOE/US\$ (81.4\%) increase due to intensity effect during the period under consideration. As a result, the increase in aggregated intensity was $1.99 \mathrm{KGOE} / \mathrm{US} \$(100 \%)$ in the same period. The result indicates that, the increase in aggregate energy intensity is due to the intensity effect (81.4\%).

Low energy intensive group contributes $13.5 \%$ in total change in energy intensity, while high-energy intensive group contribute $86.5 \%$ during the same period, shown in Table III. Again, Low energy intensive group contributes 2\% in total change in energy consumption; while high energy intensive group contribute $98 \%$ during the same period. This is explained as due to an improved efficiency of energy use in relatively high-energy intensive group. Haider, S.A. 2007

Table I: Energy consumption, GDP and Energy Intensity in Bangladesh (BBS, 1992-2008) Bangladesh

\begin{tabular}{l|c|c|c|c|c|c}
\hline & 1990 & 1995 & 2000 & 2005 & 2007 & $1990-2007$ \\
\hline EC(MTOE) & 4.8 & 6.27 & 16.8 & 24.66 & 28.71 & 235.33 \\
GDP (mill. US\$) & 25571 & 31700 & 40863 & 53234 & 60412 & 710889 \\
I (KGOE/US\$) & 0.18 & 0.197 & 0.41 & 0.46 & 0.47 & 0.33 \\
Low energy intensive sector (Agri.) & & & & & & \\
EC(MTOE) & 0.32 & 0.52 & 1.38 & 2.79 & 3.25 & 23.09 \\
GDP(mill.US\$) & 7341 & 7927 & 10055 & 11373 & 12478 & 169840 \\
I (KGOE/US\$) & 0.04 & 0.06 & 0.138 & 0.245 & 0.264 & 0.135 \\
High energy intensive sector (Ind.+Serv.) & & & & & & \\
EC(MTOE) & 4.47 & 5.74 & 15.42 & 21.86 & 25.44 & 212.2 \\
GDP (mill. US\$) & 18230 & 23773 & 30808 & 41861 & 47934 & 541049 \\
I (KGOE/US\$) & 0.24 & 0.24 & 0.5 & 0.52 & 0.53 & 0.39 \\
\hline
\end{tabular}


Table II: Calculations for factor analysis for the change in energy intensity $\left(\Delta \mathbf{I}_{0 t}\right)$

Contribution to the total change by

\begin{tabular}{c|c|c|c}
\hline Time period & Structural effect & Intensity effect & Total change \\
\hline $1991-1995$ & $0.035(127 \%)$ & $-0.065(-27 \%)$ & $-0.03(100 \%)$ \\
$1995-2000$ & $0.09(69 \%)$ & $0.04(31 \%)$ & $0.13(100 \%)$ \\
$2000-2005$ & $0.16(12 \%)$ & $1.16(88 \%)$ & $1.33(100 \%)$ \\
$2005-2007$ & $0.08(14 \%)$ & $0.49(86 \%)$ & $0.57(100 \%)$ \\
$1991-2007$ & $0.37(18.6 \%)$ & $1.62(81.4 \%)$ & $1.99(100 \%)$ \\
\hline
\end{tabular}

Unit: KGOE/US\$-2000

Table III: Contribution of groups to the total change in energy Intensity

Contribution to the total change by

\begin{tabular}{l|c|c|c}
\hline Time period & $\begin{array}{c}\text { Low energy } \\
\text { Intensive } \\
\text { group(Agri.) } \\
\text { (Structural+ } \\
\text { Intensity) }\end{array}$ & $\begin{array}{c}\text { High energy } \\
\text { Intensive } \\
\text { group } \\
\text { (Ind.+Serv.) } \\
\text { (Structural+ } \\
\text { Intensity) }\end{array}$ & Total change \\
\hline $1991-1995$ & $-0.002(0 \%)$ & $-0.03(100 \%)$ & $-0.03(100 \%)$ \\
$1995-2000$ & $0.02(15 \%)$ & $0.11(85 \%)$ & $0.13(100 \%)$ \\
$2000-2005$ & $0.17(13 \%)$ & $1.16(87 \%)$ & $1.33(100 \%)$ \\
$2005-2007$ & $0.08(14 \%)$ & $0.49(86 \%)$ & $0.57(100 \%)$ \\
$1991-2007$ & $0.27(13.5 \%)$ & $1.72(86.5 \%)$ & $1.99(100 \%)$ \\
\hline
\end{tabular}

Unit: KGOE/US\$-2000

for Pakistan, made similar type of investigation. He showed that group-1 contributes only $8.5 \%$ in total change of energy consumption, while group- 2 contributes $91.5 \%$ during the period 1960 to 1998 .

In agriculture sector the structural effect decrease by 102 fold in 2007 compared to 1991 and the intensity effect also increase by 38 fold during the same period, shown in TableIV. The aggregate effects in agriculture appeared to increase by 27 fold in 2007 compared to 1991, shown in table-4. In industrial sector the structural effect increase by 45 fold in 2007, compared to 1991 and the intensity effect also decrease by 2.8 fold during the same period shown in figure1. The aggregate effects in industry increase by 5.8 fold in 2007 compared to 1991. In service sector the structural effect decrease by 5.3 fold in 2007 compared to 1991 and the intensity effect also increase by 1345 fold during the same period shown in Table IV. The aggregate effects in service sector decrease by 20536 fold in 2007 compared to 1991.

Table IV: Sector wise Effect increase or decrease by ---fold for $\Delta \mathbf{I}_{0 t}$

\begin{tabular}{l|c|c|c|c}
\hline Agriculture & 1995 & 2000 & 2005 & 2007 \\
\hline Structural effect & -16.66 & -30.83 & -88 & -102 \\
Intensity effect & 4.3 & 18 & 36 & 38 \\
Aggregated $\left(\Delta \mathrm{I}_{0 \mathrm{t}}\right)$ & 3 & 14 & 26 & 27 \\
Industrial & & & & \\
Structural effect & 13 & 27 & 39 & 45 \\
Intensity effect & -1.2 & 3.8 & 2.9 & 2.8 \\
Aggregated $\left(\Delta \mathrm{I}_{0 \mathrm{t}}\right)$ & -0.46 & 5.6 & 5.5 & 5.8 \\
Service & & & & \\
Structural effect & 8.8 & -10.3 & 11.44 & -5.39 \\
Intensity effect & 143 & 954 & 1290 & 1345 \\
Aggregated $\left(\Delta \mathrm{I}_{0 \mathrm{t}}\right)$ & 2181 & 14331 & 19762 & 20536 \\
\hline
\end{tabular}

It can be concluded from Figure 1 that the structural effect of agriculture and service sector have negative trend, but in industrial sector it shows positive trend. The overall structural effect is positive. A positive structural effect implies a structural shift to more energy intensive economic sectors like some manufacturing industries. It also means that the

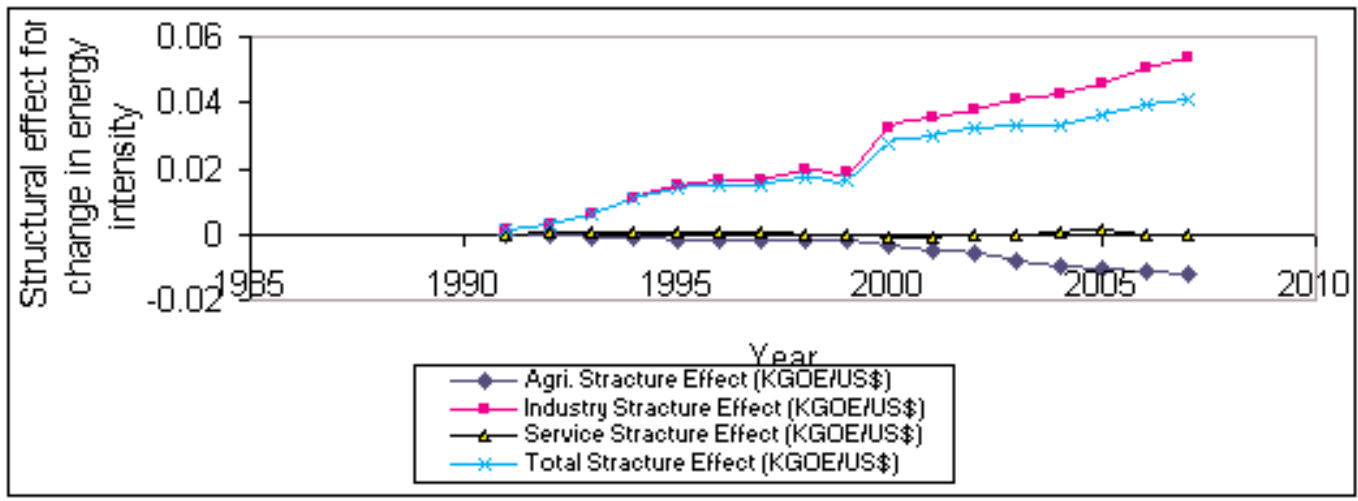

Fig. 1: Sector wise Structural effect in change in energy intensity 
share of energy intensive sectors to GDP has increased compared to base year. This is the indication of the phase transition from agriculture to industry. The positive trend of the structural effect reflects the positive growth of GDP; however, more energy will be required to produce the projected GDP. More energy intensive structural change means creation of large-scale new industrial activity with large employment opportunities. It may be concluded that our industrial sector plays a dominant role over agriculture and service sector, which can give a dynamic sustainability.

The pure energy intensity effect gives a measure of the improvement in energy efficiency, changes in technology, fuel mix changes and other factors that are not related to activity or structure. A positive effect signifies a higher energy use per unit of GDP implying worsening energy efficiency, while a negative pure intensity effect indicates an improvement in energy use per unit of GDP.

Figure 2 shows that the intensity effects of all sectors have decreasing trend. An analysis of the intensity effect, which describes the effects of technological changes and changes in production system, shows that energy intensity had decreased most in the agriculture, industry and service sectors before 2000. This is due to the technological changes of changes in production systems, and facilitated a decrease in the energy-needed fir a certain economic output. Thus the economic effectiveness of energy use increased. The aggregate intensity effect also shows the increasing trend after 2000.

If we take the structural effect and intensity effect of all sectors shown in Figure 3, we find that the structural effect increase by 41 fold in 2007 compared to 1991, and the intensity effect also increase by 12.3 fold during the same period, shown in Table V. For an increased structural effect, industrial sector plays a dominant role. Both effects show the positive trend for a chosen path of sustainable development.

Table V: Aggregate structural and Intensity effect increased or decreased by --fold for $\Delta \mathrm{I}_{0 \mathrm{t}}$

\begin{tabular}{l|c|c|c|c}
\hline Total & 1995 & 2000 & 2005 & 2007 \\
\hline Structural effect & 14 & 27 & 36 & 41 \\
Intensity effect & 0.15 & 9.8 & 12 & 12.3 \\
Total change $\left(\Delta \mathrm{I}_{0 \mathrm{t}}\right)$ & 0.5 & 11 & 14 & 14.35 \\
\hline
\end{tabular}

The factor analysis for the change in energy consumption is presented in Table VI. The change in energy consumption increases to 72.33 MTOE, -0.91 MTOE and 63.28 MTOE by activity effect, structural effect and intensity effect respectively during the period of consideration. The activity effect is the greatest in the sectors where the total energy flows are the highest. In all sub period energy consumption allows increased value by activity effect and intensity effect. In the whole study period the energy consumption decreases by structural effect. The activity and intensity effect hold positive values all throughout the period (1990-2007), indicating the strong industrialization process of Bangladesh during this period and a shift of economy towards more energy intensive sectors. The aggregate energy consumption is 134.7 MTOE in which the contribution of activity effect, structural effect and intensity effect are $53.5 \%,-0.5 \%$ and $47 \%$ respectively. It is concluded that the activity effect plays a dominant role in energy consumption during the period under consideration. Punyong, K. 2008 shows that in Thai industry the energy consumption increase by activity effect (11506.38 KTOE) and structural effect (1713.61 KTOE) but decrease by intensity effect (-139.99KTOE) during the period 1988 to 2002.

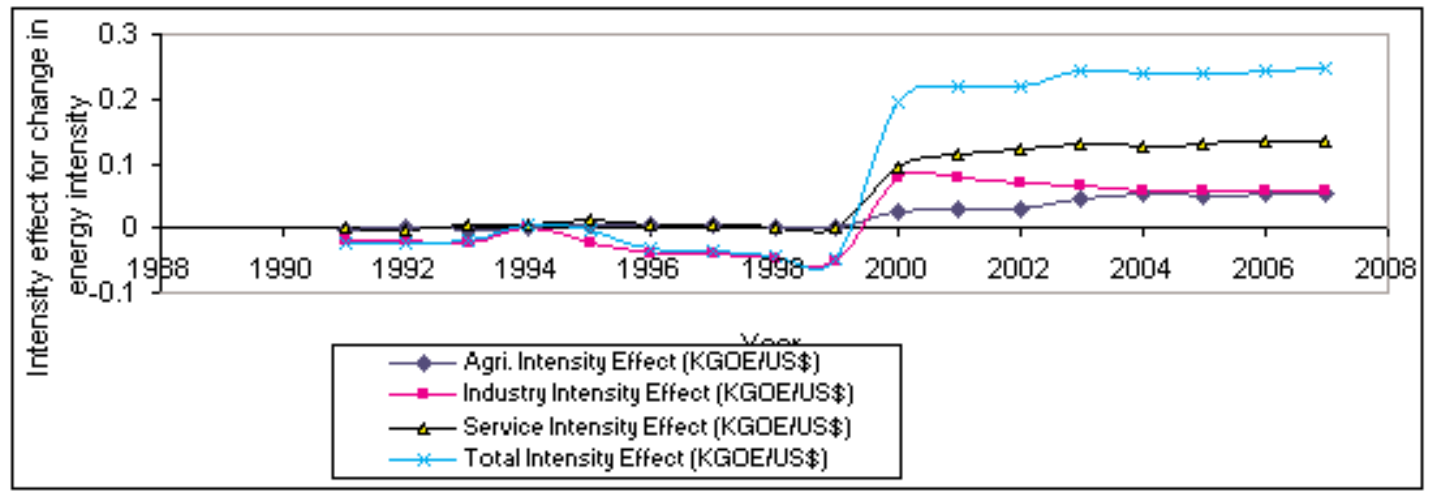

Fig. 2: Sector wise intensity effect in change in energy intensity 


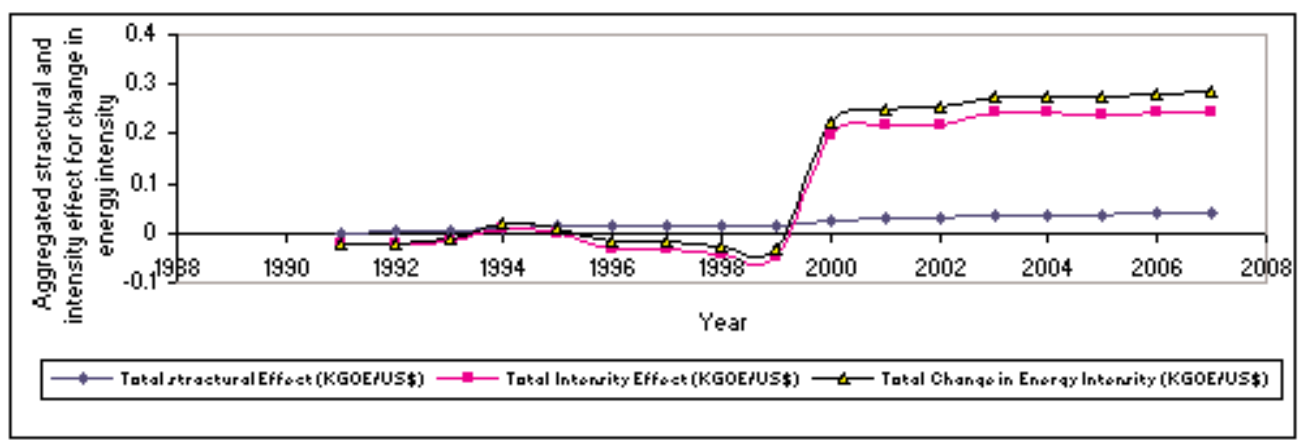

Fig. 3: Aggregate effect in change in energy intensity.

Table VI: Calculations for factor analysis for the change in energy Consumption $\left(\Delta \mathbf{E}_{0 t}\right)$ Contribution to the total change by

\begin{tabular}{l|c|c|c|c}
\hline Time period & Activity effect & Structural effect & Intensity effect & Total change \\
\hline $1991-1995$ & $3.26(259 \%)$ & $-0.35(-28 \%)$ & $-1.65(-131 \%)$ & $1.26(100 \%)$ \\
$1995-2000$ & $11.84(91 \%)$ & $-0.55(-4 \%)$ & $1.67(13 \%)$ & $12.96(100 \%)$ \\
$2000-2005$ & $35.47(45.3 \%)$ & $0.044(.05 \%)$ & $42.72(54.5 \%)$ & $78.23(100 \%)$ \\
$2005-2007$ & $21.76(51.5 \%)$ & $-0.05(-0.1)$ & $20.55(48.6 \%)$ & $42.26(100 \%)$ \\
$1991-2007$ & $72.33(53.5 \%)$ & $-0.91(-0.5 \%)$ & $63.2847 \%)$ & $134.7(100 \%)$ \\
\hline
\end{tabular}

Unit: MTOE

Contributions of different groups to the total change in energy consumption are reported in Table VII. High-energy intensive group contributes a large increase, while low energy intensive group contributes a small increase in the total increase of aggregate energy consumption during the period under consideration. Results indicate that the increase in aggregate energy consumption was 134.71 MTOE in which high-energy intensive group contributes $131.65 \mathrm{MTOE}$ (98\%) and low energy intensive group contributes 3.06 MTOE (2\%) in the study period of 1991 to 2007. These results reconfirm the preceding findings that high-energy

Table VII: Contribution of groups to the total change in energy Consumption ( $\Delta$ Eot)

Contribution to the total change by

\begin{tabular}{l|c|c|c}
\hline & $\begin{array}{c}\text { Low energy } \\
\text { Intensive } \\
\text { group(Agri.) }\end{array}$ & $\begin{array}{c}\text { High energy } \\
\text { Intensive } \\
\text { group } \\
\text { (Ind.+Serv.) }\end{array}$ & Total change \\
\hline $1991-1995$ & $-1.13(-90 \%)$ & $2.39(190 \%)$ & $1.26(100 \%)$ \\
$1995-2000$ & $-1.72(-13 \%)$ & $14.68(113 \%)$ & $12.96(100 \%)$ \\
$2000-2005$ & $3.74(5 \%)$ & $74.49(95 \%)$ & $78.23(100 \%)$ \\
$2005-2007$ & $2.18(5 \%)$ & $40.08(95 \%)$ & $42.26(100 \%)$ \\
$1991-2007$ & $3.06(2 \%)$ & $131.65(98 \%)$ & $134.71(100 \%)$ \\
\hline
\end{tabular}

Unit: MTOE intensive group is mainly responsible for improved efficiency of energy uses in the country, during the study period.

For change of energy consumption, in agriculture sector, activity effect increase by 124.5 fold, structural effect decrease by 733 fold and intensity effect also increase by 61 fold in 2007 compared to 1991, shown in Table VIII. The aggregate effects in agriculture increase by 38 fold in the

Table VIII : Sector wise effect increase or decrease by ----fold for $\Delta \mathbf{E}_{\mathbf{~} t}$

\begin{tabular}{l|c|c|c|c}
\hline Agriculture & 1995 & 2000 & 2005 & 2007 \\
Activity effect & 8.9 & 36 & 96 & 124.5 \\
Structural effect & -198 & -268 & -622 & -733 \\
Intensity effect & 4.77 & 22.56 & 53 & 61 \\
Aggregated $\left(\Delta \mathrm{E}_{0 \mathrm{t}}\right)$ & 12.45 & 11.16 & 31 & 38 \\
Industrial & & & & \\
Activity effect & 7.5 & 29 & 52 & 66 \\
Structural effect & 14 & 35 & 59 & 76 \\
Intensity effect & -1.2 & 4.7 & 4.4 & 4.6 \\
Aggregated $\left(\Delta \mathrm{E}_{0 \mathrm{t}}\right)$ & 0.9 & 14 & 20.5 & 25 \\
Service & & & & \\
Activity effect & 8 & 30.6 & 64 & 82 \\
Structural effect & 9.6 & -13 & 17.6 & -9.5 \\
Intensity effect & 155 & 1206 & 1940 & 2223 \\
Aggregate $\left(\Delta \mathrm{E}_{0 \mathrm{t}}\right)$ & 15.6 & 86 & 154.5 & 185 \\
\hline
\end{tabular}


whole study period. In industrial sector the activity effect increase by 66 fold, structural effect increase by 76 fold and the intensity effect also increase by 4.6 fold in 2007 compared to 1991 . The aggregate effects in industry increase by 25 fold in 2007 compared to 1991. In service sector the activity effect increase by 82 fold, structural effect decrease by 9.5 fold and the intensity effect also increase by 2223 fold in 2007 compared to 1991, shown in Table VIII. The aggregate effects in service sector decrease by 185 fold in 2007 compared to 1991.

It is concluded from table- 8 that the activity effect increase faster in industrial compare than agriculture and service sector, again structural effect increased in industry sector and decreased in agriculture and service sector which indicates that our economy shifting form agriculture to industrial and which is vital and necessary for sustainable development of Bangladesh. The intensity effect also decreases in industrial sector up to 1999; this is one of the indications of sustainable development of Bangladesh.

If we aggregate the activity effect, structural effect and intensity effect of all sectors, we found that the activity effect increase by 76 fold in 2007 compared to 1991 . The structural effect decrease by 0.3 fold during the same period and the intensity effect also increase by 18 fold during the mentioned period, shown in Table IX. The aggregate changes in energy consumption increase by 56 fold in the whole studied period. In the aggregate change in energy consumption activity and intensity effect play a dominant role, which is positive sign for sustainable development. On the other hand structural effect decreases, which also indicates that the country is forwarding towards the path of sustainability.

Table IX: Aggregate activity, structural and Intensity effect increased or decreased by---fold for $\Delta \mathbf{E}_{\text {ot }}$

\begin{tabular}{l|c|c|c|c}
\hline Total & 1995 & 2000 & 2005 & 2007 \\
\hline Activity effect & 7.8 & 30 & 59.5 & 76 \\
Structural effect & -6 & 6 & -3.5 & -0.3 \\
Intensity effect & 0.18 & 11 & 16 & 18 \\
Total change $\left(\Delta \mathrm{E}_{0 \mathrm{t}}\right)$ & 2.3 & 29 & 46.5 & 56 \\
\hline
\end{tabular}

\section{Conclusion}

For the present analysis we had to depend on the existing data. The small uncertainties that one can presume in the present is lightly to be affected by the uncertainty in the data used. However, data collection is a historical process and we cannot do much about this uncertainty. Assuming that the errors in the collection of data are random, we can take that the errors will cancel out. This is the basic assumption in using statistical method.

We have used decomposition method as a standard technique for analyzing the energy intensity and energy efficiency, which has the advantage that a comparison can be drawn between Bangladesh and other developing countries. For such comparison it is important that a common excepted method is used for the analysis of activity effect, intensity effect and structural effect for the period of 1991 to 2007 with the following results.

1) The energy intensity of low energy intensive group increased by 6.6 fold during the period 1990 to 2007, on the other hand the energy intensity in high-energy intensive group increased by 2.2 fold during the same period. The increase in aggregate energy intensity is due to the intensity effect (81.4\%).

2) In all sub-period high energy intensive group shows large change (86.5\%) and low energy intensive group shows small changes $(13.5 \%)$ in total energy intensity changes. This could be a result of improved efficiency of energy use of relatively high-energy intensive group. Again, it can be concluded that the structural effect of agriculture and service sector shows negative trend, but in industrial sector it shows positive trend. The overall structural effect is positive, due to the positive trend of industrial sector and this is the indication of the phase transition from agriculture to industry.

3) In the case of change in aggregate energy consumption the activity effect increase faster in industrial compare than agriculture and service sector, again structural effect increased in industry sector and decreased in agriculture and service sector.

4) The aggregate energy consumption is $134.71 \mathrm{MTOE}$ in which the contribution of activity effect, structural effect and intensity effect are $53.5 \%,-0.5 \%$ and $47 \%$ respectively. Group- 1 contributes $2 \%$ in total change in energy consumption, while group- 2 contributes $98 \%$ during the period. It is concluded that the activity effect plays a dominant role in energy consumption during the period under consideration. These results reconfirm preceding findings that high-energy intensive group is mainly responsible for improved efficiency of energy uses in the country, during the study period. 


\section{References}

Bangladesh Bureau of Statistics (BBS). 1992-2008. Statistical pocketbook of Bangladesh. Ministry of Finance and Planning, Govt. of the People's Republic of. Bangladesh, Dhaka.

Boyd G. A., Hanson D. A. and Sterner T. (1988). Decomposition of changes in energy strength: A comparison of the Divisa index and other methods, Energy Econ. 10: 309-312.

Dobbin C. P. and Claire P. (1988). Declining energy strength in the US manufacturing sector. Energy J. 9: 109-135.

Haider S. A. and Ali L. (2007). Derivates of energy consumption and energy strength in Pakistan: An application of complete decomposition model. Research $J$. of Applied Science. 2(4): 484-488.

Howarth R. B. (1991). Energy use in US manufacturing: The impact of the energy shocks on sectoral output, industry structure and energy strength. J. Energy and Dev. 14: 175-191.
Howarth R. B. and Schipper L. (1992). Manufacturing energy use in eight OECD countries: trends through 1988. Energy J. 12: 1540

Park S. H. (1992). Decomposition of industrial energy consumption, Energy Econ. 13: 265-270.

Park S. H., Dissmann B. and Nam K. Y. (1993). A crosscountry decomposition analysis of manufacturing energy consumption. Energy J. 18: 843-857.

Punyong K., Taweekun J. and Prasertsan S. (2008). Evaluation of energy saving in Thai industry by 3-D decomposition method. Asian J. Energy Environ. 9(1 \&2): 15-37.

Reitler W., Rudlof M. and Schaefer H. (1987). Analysis of factor influencing energy consumption in industry: A revised method, Energy Econ. 9: 145-148.

Sun J. W. (1996). Quantitative analysis of energy consumption, efficiency and saving in the world, 1973-1990. Turku School of Economic Press.

Received : May 05, 2010;

Accepted : April 25, 2011 